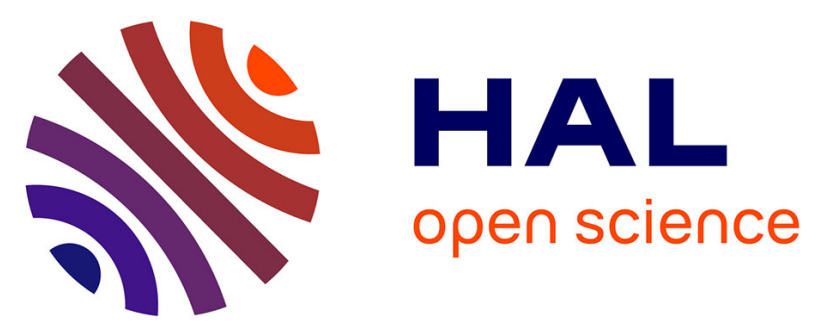

\title{
Influence of an original manufacturing process on the properties and microstructure of $\mathrm{SiC} / \mathrm{SiC}$ tubular composites
}

\author{
James Braun, Cédric Sauder, Jacques Lamon, Fanny Balbaud-Célérier
}

\section{To cite this version:}

James Braun, Cédric Sauder, Jacques Lamon, Fanny Balbaud-Célérier. Influence of an original manufacturing process on the properties and microstructure of $\mathrm{SiC} / \mathrm{SiC}$ tubular composites. Composites Part A: Applied Science and Manufacturing, 2019, 123, pp.170-179. 10.1016/j.compositesa.2019.04.031 . hal-02146149

\author{
HAL Id: hal-02146149 \\ https://hal.science/hal-02146149
}

Submitted on 22 Oct 2021

HAL is a multi-disciplinary open access archive for the deposit and dissemination of scientific research documents, whether they are published or not. The documents may come from teaching and research institutions in France or abroad, or from public or private research centers.
L'archive ouverte pluridisciplinaire HAL, est destinée au dépôt et à la diffusion de documents scientifiques de niveau recherche, publiés ou non, émanant des établissements d'enseignement et de recherche français ou étrangers, des laboratoires publics ou privés.

\section{(ㄷ)(1) $\$$}

Distributed under a Creative Commons Attribution - NonCommercial| 4.0 International 
Version of Record: https:/www.sciencedirect.com/science/article/pii/S1359835X19301666 Manuscript_3475f7ccef29859bfb0a0468d9890748

Title: Influence of an original manufacturing process on the properties and microstructure of $\mathrm{SiC} / \mathrm{SiC}$ tubular composites

James Braun ${ }^{\mathrm{a}}$ - Cédric Sauder ${ }^{\mathrm{a}}$ - Jacques Lamon ${ }^{\mathrm{b}}$ - Fanny Balbaud-Célérier ${ }^{\mathrm{c}}$

aDEN-Service de Recherches Métallurgiques Appliquées (SRMA), CEA, Université Paris-Saclay, F-91191, Gif-sur-Yvette, France

baboratoire de Mécanique et Technologie (LMT), UMR 8535, CNRS-ENS-UPMC, Cachan, France 'DEN-Service d’Etudes Analytiques et de Réactivité des Surfaces (SEARS), CEA, Université Paris-Saclay, F-91191, Gif-sur-Yvette, France

Keywords: A. Ceramic-matrix composites (CMCs); B. Mechanical properties; C. Acoustic emission;

D. icrostructural analysis.

ABSTRACT:

$\mathrm{SiC} / \mathrm{SiC}$ composites reinforced with Hi-Nicalon $\mathrm{S} 3^{\text {rd }}$ generation $\mathrm{SiC}$ fibers are promising candidates for high temperature aeronautical applications and fuel cladding in nuclear reactors. An original patented process was used to produce $\mathrm{SiC} / \mathrm{SiC}$ tubular samples for dimensional and tensile mechanical characterizations. The process route is described in detail to further understanding of specific features. $\mathrm{SiC} / \mathrm{SiC}$ samples show a low porosity and excellent geometrical tolerance. Highly reproducible tensile mechanical behavior is observed with good mechanical failure characteristics. Some specific features were highlighted during mechanical characterizations with loading/unloading sequences. For instance, an original mechanical behavior was observed before the onset of matrix multicracking (deviation from linearity). To our knowledge, it is the first time that this kind of behavior has been detected on $\mathrm{SiC} / \mathrm{SiC}$ composites, due to the processing route leading to the microstructure of specific samples.

\section{Introduction}

Among the Ceramic Matrix Composites (CMC), SiC/SiC composites and affiliates have aroused interest for challenging high-temperature applications such as aerospace [1], aeronautics [2], defense [3] or nuclear applications [4] for their excellent mechanical properties [5] and oxidation resistance [6] at 
elevated temperature. Initially considered for fusion application (breeding blankets) [7] [8], SiC/SiC can also improve performance and safety of current nuclear reactors in the framework of EATF [9] but is also one of the few options for generation IV nuclear reactor core materials. For instance, Gas-cooled Fast Reactors (GFR) are designed to operate at high temperatures even in nominal conditions, so the fuel cladding has to sustain temperatures between 450 and $1000^{\circ} \mathrm{C}$ for several years. Moreover, the fuel cladding will have to maintain its dimensions and integrity in extreme situation (up to $1600^{\circ} \mathrm{C}$ ) [10]. In this aim, the $\mathrm{SiC} / \mathrm{SiC}$ tubular composites reinforced with $3^{\text {rd }}$ generation Hi-Nicalon $\mathrm{S}$ fibers are potential candidates that can meet the GFR criteria and are, currently, the more advanced cladding solution [11]. The Chemical Vapor Infiltration (CVI), enabling also the pyrocarbon interphase deposition, was applied for densification. This process was chosen because the SiC matrix deposited by this technique leads to better properties under irradiation [12]. A three-layered tubular fibrous structure was chosen for the texture, made of filament winding and/or 2D braiding [4], which achieves a good level of surface roughness $\left(R_{a}<3 \mu \mathrm{m}\right)$, with a final cladding thickness below $1 \mathrm{~mm}$ (Fig 1$)$. Tubular shaped CMCs were not studied extensively, especially on such fine structure, due to the lack of application outside of the nuclear industry.

For high temperature heat exchangers, if thick tubes are needed (over $1 \mathrm{~mm}$ and up to $10 \mathrm{~mm}$ ) [13], the structure of the material is commonly made of woven tissues of carbon or silicon carbide fibers, rolled on a mandrel and embedded in a resin. Its pyrolysis combined with Melt Infiltration (MI) lead to the sample densification [13] [14]. However, this technique is not suitable for thin layer materials considered for fuel cladding $(<1 \mathrm{~mm})$, which is around the thickness of the $2.5 \mathrm{D}$ woven fabrics made of Hi-Nicalon S fibers, even though $80 \%$ dense materials can be manufactured [15]. The MI is also not compatible with nuclear applications due to swelling mismatch between $\mathrm{SiC}$ and $\mathrm{Si}$ under irradiation [16].

Some cylindrical structures were also developed for aerospace applications, such as turbine vanes and blades, out of Sylramic fibers by alternate methods (2D and 3D braiding, filament winding, pin-weave, orthogonal-weave, ...) with a matrix made of a combination of $\mathrm{CVI}$ and melt infiltration. It was noted that this tube structure induces addition constituent and process-related issues that are not experienced 
for flat panels: fiber bending, limited fiber fraction in key directions and limited interphase and matrix formation caused by one-sided infiltration from the mandrel [17]. Hot pressing may be employed for matrix densification [18] but the necessity of high temperature may diminish the fibers mechanical properties [19]. This issue can also occur for NITE-based materials [20], which leads to composites with low level of porosities.

In previous studies, the laboratory has manufactured 3D Interlock tubes, while the material reaches high damage tolerance, this technique leads to very important level of porosities [21].

In the present work, specific $\mathrm{SiC} / \mathrm{SiC}$ cladding sections were produced out of filament winding and 2D braiding along with CVI densification. Both techniques can produce down to $300 \mu \mathrm{m}$ thick composites. These methods, along with the use of a specific mandrel, allow the production of materials that reach excellent dimension tolerance.

A lack of data on manufactured CMC tubes is noted. Mainly, studies are focused on the hoop [22] [23] or the flexural [15] strength. Thus, tensile mechanical behavior of samples (produced with an original manufacturing process) and their reproducibility were assessed. Loading/unloading cycled specific tensile tests were performed to achieve data regarding damage evolution and the friction mechanism as a function of the strain/stress levels, which were not evaluated in previous multiaxial testing [24]. After being damaged at several levels and up to ultimate failure, the crack density of the composites was measured and compared to the cumulated acoustic emission signal (number of events, representative of the number of cracks generated during mechanical solicitation) [25]. Finally, the thermal residual stresses, due to thermomechanical mismatch between the matrix and the fibers, were determined both experimentally and by modelling [26]. All these characterizations were used to discuss the specificity of tensile mechanical behavior of these $\mathrm{SiC} / \mathrm{SiC}$ cladding specimens.

Fig. 1.

2. Materials and method 


\section{1. $\mathrm{SiC} / \mathrm{SiC}$ composites elaboration}

\subsubsection{Fibrous reinforcement processing}

Third generation Hi-Nicalon S (NGS supplier) SiC fibers were chosen as SiC/SiC CMC (Ceramic Matrix Composite) reinforcement. The manufactured $\mathrm{SiC} / \mathrm{SiC}$ composite material has a 3 successive layer structure. The inner layer is made of $\pm 45^{\circ}$ filament wound structure (usually modelled as laminated structure) and the two others of $\pm 45^{\circ} 2 \mathrm{D}$ braiding structure (modelled as twill fabric). In this aim, a 32 carriers 2D braiding machine was used. All the layers have similar thicknesses $(\approx 300 \mu \mathrm{m})$. The filament winding process (interlaced plies) leads to a very good internal circular shape for tubular structure in contrast with the 2D braiding (cross plies) that leads to more irregular internal and external surfaces [4]. Parameters (speed, fiber tension, etc...) have to be chosen wisely to avoid any tow fiber fracture during manufacturing. To obtain similar characteristics under tensile and swelling (internal pressure) mechanical solicitations, the fibers orientation was fixed to $\pm 45^{\circ}$ [24]. The fiber structure is processed on a mandrel that has to match several criteria. At first, it has to be chemically inert at high temperature $\left(800\right.$ to $1100^{\circ} \mathrm{C}$ ) to withstand the CVI densification process (MTS, $\mathrm{H}_{2}, \mathrm{HCl}, \ldots$ ). Secondly, its removal has to be simple, without damaging the composite. At last, this mandrel must have a sufficient stiffness and be easy to grind to reach a high tolerance diameter dimension along its length, directly influencing the dimension tolerance of the composite. In addition, the silica glass mandrel was retained because it can be easily removed by hydrofluoric acid chemical etching [27]. Finally, the fibrous reinforcement has respectively an external diameter, a length and a fiber volume fraction of $9.4 \mathrm{~mm}, 200 \mathrm{~mm}$ and $\approx 40$ to $45 \%$.

\subsubsection{Densification / Machining}

Chemical Vapor Infiltration (CVI) was used for the densification of fibrous reinforcement. First, a 30 $50 \mathrm{~nm}$ pyrocarbon interphase and a few micrometers of SiC were successively deposited to give, respectively, the composites expected mechanical properties [28] and the material a sufficient rigidity for mandrel withdrawal [27]. The SiC matrix volume fraction is around $5-20 \%$ after this step (consolidation step), so that the mandrel can be removed by a HF chemical etching, dissolving the silica. 
In the case that the mandrel would have not been withdrawn, the densification would be incomplete on the inner side. To complete the densification, a second CVI densification step is repeated. At the end of this second step, matrix volume fraction is between 30 and $40 \%$. Centerless grinding is then employed to reach desired external dimensions. An ultimate CVI densification is then executed for seal coat deposition. After this last step, the matrix volume fraction reaches 40 to $55 \%$. The internal surface is then grinded (running-in process) to reach the final internal dimension with $\pm 0.01 \mathrm{~mm}$ tolerance. The final porosity volume fraction of the composites is below $10 \%$. The fibers and matrix volume fractions cannot be measured precisely because of the grinding steps. If the hypothesis that no fibers remained undamaged and that only the SiC matrix is removed during the grinding steps, the mean values (and SD) of the fiber, matrix and porosities volume fractions would be $42.26(0.53) \%, 50.05(0.94) \%$ and 7.70 $(0.72) \%$, respectively. However, those values can only be considered as qualitative values. The tube cross-section was observed by X-ray tomography (Fig. 2). Cylindrical alumina standards and an optical profilometer (SCAN 52 TESA Technology) were used to determine respectively the internal $(7.88 \mathrm{~mm})$ and the external $(9.58 \mathrm{~mm})$ average diameters along the length of the tubes. Geometrical characteristics of the manufactured composites clads are presented in Table 1.

\section{Fig. 2.}

\section{Table 1}

\subsection{Mechanical characterization}

\subsubsection{Introduction}

Tubular test specimens were cut at $65 \mathrm{~mm}$ length before uniaxial tensile tests. The used procedure is described in the ISO 20323 standard [29] and is shown in Fig. 3. An epoxide structural glue (3M ScotchWeld $^{\mathrm{TM}} 9323 \mathrm{~B} / \mathrm{A}$ ) allows the fixation of the test specimens with the end collars adjusted to the composites section. The whole, i.e. the tubular test specimen and the end collars, was installed on the mechanical testing machine (INSTRON 2404). The upper part of the sample was screwed on the $25 \mathrm{kN}$ load cell (HBM U10M), fixed on the displaceable cross-rail. The lower part was glued on the machine stationary base. The longitudinal strain was measured with an INSTRON 2620-603 extensometer 
( $\pm 1 \mathrm{~mm}$ course) with a $25 \mathrm{~mm}$ gauge length. The diametric strain was measured with a MTS 632.19F-20 ( $\pm 1 \mathrm{~mm}$ course) sensor. These extensometers were calibrated with a high-resolution numeric calibrator $(0.1 \mu \mathrm{m})$. An acoustic emission sensor coupled with a signal conditioner and data acquisition system (resp. VS700-D and ASCO-DAQ2 by Vallen Systeme) $(90-295 \mathrm{kHz})$, fixed on the upper end collar, was systematically used to detect the matrix multicracking and the possible microstructural coupling. The measured signal is presented as a cumulated signal and corresponds to events. To avoid noise influence, only the acoustic emission over $50 \mathrm{~dB}$ were counted, corresponding to the background plus $10 \mathrm{~dB} . A E$ and $A E_{\max }$ are the number of events for a given level of stress reached and the number of events at the sample fracture, respectively.

Displacement speeds were controlled through the displaceable cross-rail, ranging from 0.05 to $0.2 \mathrm{~mm} / \mathrm{min}$. No effect on the mechanical behavior of those materials in this strain rate range has never been observed. 7 unloading - reloading cycles were done for some tensile tests at different levels of longitudinal strains before unloading $(0.05,0.1,0.15,0.2,0.3,0.4$ and $0.5 \%)$. The speed level was increased along with the strain, to diminish the test duration, while still having a good precision at the lowest strains.

\subsubsection{Analysis of the unloading - reloading cycles}

The analysis of the unloading - reloading cycles give some information on damage evolution (matrix multi-cracking) in the composites microstructure during uniaxial mechanical loading [30] [31] (Fig. 4). The consequence is a progressive decrease of the longitudinal elastic modulus $(E)$, along with the increase of the anelastic residual strains after unloading $\left(\varepsilon_{r}\right)$, the full width at half maximum $(\Delta \varepsilon)$ and the area of the cycles $(\Delta W)$, corresponding to the energy dissipated in the material. The evolution of those parameters are characteristic of the damaging and allows a better understanding of the microstructural changes in the material during mechanical loading.

Before matrix cracking, the composite exhibit a linear elastic mechanical behavior, allowing the measurement of the initial Young's modulus $\left(E_{0}\right)$. Therefore, cycles below this domain are closed. Beyond this domain, matrix multicracking takes place. Cycles are open and can take the appearance of 
an ellipse with or without stiffening at the end of the unloading sequence. This possible stiffening, schematized on Fig. 4, is the consequence of the early reclosing of the matrix cracks and/or is due to the fibers roughness. In all the case, $\Delta \varepsilon$ and $\Delta W$ always increase along with the mechanical loading and constitute a relevant parameter to follow the material damage progress during mechanical tensile test [32] [33]. The area of the cycles is characteristic of the dissipated energy in the material, hence the hysteresis loop. It increases as a consequence of the dissipative frictional mechanisms occurring at the interfaces. The shape of the cycles can also evolve during a test as a function of the reached longitudinal strain. Fig. 5 shows the method applied to determine both the initial Young's modulus $\left(E_{0}\right)$ and the elasticity modulus $(E)$ during the unloading - reloading tensile tests. The latter is determined by measuring the slope of the line passing through the summit of the cycle $(\sigma, \quad)$ and the median point of the cycle for a stress [34]. The evolution of the elastic modulus is generally given thanks to the evolution of the reduced modulus, , as a function of the applied stress or strain, which is pertinent to follow the matrix multicracking evolution of the composite. For some specific composites structure (mechanical solicitation in one of the reinforcement axes and a good damage tolerance), when the longitudinal strain is close to failure (saturation of matrix multicracking), only the fibers orientated in the loading axis ensure the mechanical loading. Then, the reduced modulus reaches an asymptotic value, corresponding to the fiber fraction Young's modulus aligned in the mechanical solicitation direction. This value is given by Eq. (1) for a 2D plate composite solicited at a $\Phi$ angle towards the tows direction [35]. $E_{f}$ and $V_{f}$ are the tow Young's modulus and the fiber volume fraction, respectively. However, it has never been highlighted that this formula is also suitable for $\mathrm{a} \pm 45^{\circ}$ angle tubular structure.

The evolution of the reduced Poisson's ratio $\left(v_{i} / v_{0}\right)$ as a function of the applied stress usually follows the same trend that the longitudinal Young's modulus. However, a decrease to zero reveals the reduction of the lateral interactions, attributed to debonding at the fiber/matrix interface [33]. The 
residual strains $\left(\varepsilon_{a n}\right)$ correspond to the longitudinal strains observed after complete unloading, over the composite elastic domain (Fig. 4), which take their origin from several phenomena:

- $\quad$ The release of the residual axial stresses (parallel to the loading direction) coming from the CVI densification (temperature going up to $1100^{\circ} \mathrm{C}$ ). The residual thermal strains $\left(\varepsilon_{t}\right)$ can be determined from the total residual strains [36] [37];

- $\quad$ friction mechanisms at different energies, which generate partial irreversible sliding [38];

- mechanical obstruction to the complete reclosing of the cracks due to the fibers roughness and/or fiber and matrix debris whose formation is enhanced by load cycling, leading to an increase in the sliding resistance at the end of the unloading sequence [38].

Fig. 4.

Fig. 5.

3. Results

3.1. Tensile behavior

The typical envelope of the strain/stress response of the manufactured SiC/SiC tubes, extracted from the cycled tensile tests, is presented along with the normalized acoustic emission $\left(A E / A E_{\max }\right)$ as function of the longitudinal strain and the fracture surface after ultimate failure of the sample in Fig. 6. The $A E$ signal corresponds to the whole events occurring, even during the unloading sequences, that is why is not strictly growing as a function of the longitudinal strain. Different regimes are observed. At the beginning, the material exhibits a linear elastic response, whose slope is the material initial Young's modulus $\left(E_{0}\right)$. The deviation from linearity quickly appears ( $f$ or $\varepsilon_{l}=0.012 \%$ and $\sigma_{l}=34 \mathrm{MPa}$ ) (Table 2 ), at point (A). However, the latter is not accompanied by any acoustic emission signal and slowly deviates from linearity. This phenomenon has never been observed on 2D SiC/SiC plates, even for offaxis solicitations [39]. It can be concluded that it is not the consequence of the beginning of matrix multicracking. Indeed, the first acoustic signal $\left(\varepsilon_{A E}=0.053 \%\right.$ and $\left.\sigma_{A E}=112 \mathrm{MPa}\right)$, corresponding to the appearance of the first matrix crack, induces a clear and distinct change in the slope of the longitudinal strain/stress curve (Fig. 6) (B). Around $200 \mathrm{MPa}(\mathrm{C})$, an increase in the stress response is 
again observed, evidencing a strengthening mechanism following the load displacement on the fibers, until ultimate failure (D). Afterwards, the AE follows an almost linear evolution as a function of the applied strain. The cumulative AE count is proportional to the number of cracks generated in the composite [40]. It should be noted that the acquisition device only allows a simple counting over a predefined threshold. The analysis of the AE energy signal (rather than AE cumulative count) for similar tests (analogous materials and mounting) exhibit a saturation above a stress of $200 \mathrm{MPa}$ and a $0.5 \%$ longitudinal strain [24]. The same Identical regimes are observed on diametric strain/stress curve. The fracture surface gives a qualitative evaluation of the interfacial strength. On the internal side of the tube (filament winding structure), the debonding length $\left(L_{d}\right)$, i.e. extracted from the matrix sheath, is shorter from the one observed on the external side (2D braiding structure). These debonding lengths (several dozens of micrometers) are distinguishing features of a moderate bonding.

To verify the homogeneity and reproducibility of the manufacturing process, 8 different tubes (REF 1 to REF 8) were tested following the same procedure. Fig. 7 shows an assessment of the longitudinal strain/stress envelopes under uniaxial tensile loading. Table 2 summarizes the tensile characteristics of all the tested $\mathrm{SiC} / \mathrm{SiC}$ tubular specimens. A very good reproducibility of the mechanical behavior is observed. A 279 ( \pm 13$)$ MPa stress at fracture was determined. Given the fact that some of the samples are issued from different lots of fibers and that there were not manufactured on the same mandrel, it can be concluded that the employed process lead to homogeneous tubes. The noticeable differences appear mainly for high strain and stress levels and are mainly due to discrepancies in the defect levels in the composites, slighting changing the Weibull moduli of the composites and, as a consequence, the material ultimate tensile strength [41].

Fig. 6.

Fig. 7.

Table 2

3.2. Cycle analysis

A representative tensile stress-strain curve of a specimen (with unloading - loading sequences) is presented in Fig. 8. The extended hysteresis loops are characteristic of sliding with high fiber/matrix 
interface friction. The impeded crack closing at the end of the unloading step is present, inducing an apparent stiffening [38]. It appears that over a given threshold (longitudinal strain of $0.2 \%$ ), during the reloading, the stress does not reach the exact value of the maximal stress obtained before the previous unloading sequence for a similar strain. This phenomenon tends to reveal that, over a given damage level, additional damages take place during further tensile mechanical solicitations, even for lower stresses than the maximum stress previously reached. This may be related to the opening of the preexisting microcracks and/or to the abrasion of the different interfaces due to friction. This result is confirmed by the AE signal analysis (Fig. 8), where the count increase below the maximum strain and stress reached during the previous loading cycle.

The evolution of reduced elastic modulus $\left(E / E_{0}\right)$ as a function of the maximum stress applied before unloading sequences is presented Fig. 9. The whole tests show a good homogeneity of the processed specimens. The regimes highlighted on Fig. 6 can also be observed through the reduced modulus. Its value is fixed to the unity until the beginning of the loss of linearity of the tensile strain/stress curve [33] (A). The reduced modulus at about $100 \mathrm{MPa}$ of longitudinal stress correspond to the one measured during the unloading of the $0.05 \%$ cycle, i.e. at the onset of AE, highlighting the beginning of the matrix multi-cracking (B). Therefore, a noticeable decrease (20\%) appears before the beginning of the matrix multicracking $\left(\sigma_{A E}\right)$, which is not linked to any damaging of the material upon mechanical sollicitation. Moreover, the main decrease of the composites reduced modulus occurs just above this domain in a small stress range [100 - $150 \mathrm{MPa}$. The measurements were stopped at a longitudinal strain of $0.5 \%$, corresponding to an applied stress of about $200 \mathrm{MPa}$. At this level, the reduced modulus seems to converge towards an asymptote, following the load displacement on the fibers and a saturation of the matrix multicracking (C). As mentioned earlier, the evolution of AE energy signal is characterized by a saturation at high stress and strain [24] whereas the AE event signal evolves linearly. Therefore, over those level of deformation, the contribution of the strongest events decrease a lot, in favor of low energy ones, such as interfacial debonding or interfacial shear cracking [42]. A combination between AE energy and events signal would lead to a better understanding of the material properties under mechanical loading. 
The limit value of the reduced modulus is given on a 2D plate composite by relation (1).

The tow Young's modulus (319 GPa)[43] was taken into account instead of the fiber one (372 GPa)[44].

Given a fiber volume fraction between 40 and $45 \%$ and a $45^{\circ}$ angle, the ultimate reduced Young's modulus is comprised between 0.114 and 0.129 . The later asymptotes are plotted in Fig. 9. Therefore, this relation seems to be also available for $2 \mathrm{D}$ tubular $\mathrm{SiC} / \mathrm{SiC}$ composites, up to the composites ultimate failure (D). However, mechanical testing cannot be conducted at such high levels of damage because the material become sensitive to fatigue testing over $70 \%$ of the ultimate tensile strength [45].

\section{Fig. 8.}

Fig. 9.

The longitudinal residual strains are anelastic strains $\left(\varepsilon_{a n}\right)$, which appears during the composite damaging under mechanical loading (Fig. 4). Two different contributions can be extracted. Residual thermal strains are generated in the composite as a consequence of the CVI process (during cooling down to room temperature) due to the mismatch of thermomechanical properties of its constituents (fiber, interphase and matrix). During a uniaxial tensile test, those axial stresses are released consecutively to the matrix multicracking (debonding of fiber and matrix) and induced a contribution $\varepsilon$ in $\varepsilon_{a n}$. The other component, $\varepsilon_{f}$, is the partial irreversible sliding and/or the mechanical hindrance of the cracks reclosing. The whole is linked by Eq. (2):

$\varepsilon$ corresponds to the intersection of the asymptotes of the curves during the reloading step at the end of the cycle and the abscissa axis for all cycles (Fig. 10 (a)). All the curves cross at the same point at about $35 \mathrm{MPa} \pm 5 \mathrm{MPa}$. This point corresponds to the axial thermal residual strains in the fibrous reinforcement after manufacture. The evolution of $\varepsilon_{a n}, \varepsilon_{T}$ and $\varepsilon_{f}$ as a function of the maximum stress reached before unloading sequences are presented in Fig. 10 (b). A saturation of the thermal longitudinal residual strains appears at high stress (over $200 \mathrm{MPa}$ ), which may again confirm the saturation of the matrix multicracking. In the same way, the irreversible sliding strains $\left(\varepsilon_{f}\right)$ also seems to 
tend to an asymptotic value over $200 \mathrm{MPa}$. On the contrary, the anelastic residual strains increase quite linearly with the loading stress level.

The evolution of the area and the full width at half maximum of the cycles are representative of the energy dissipated in the material and the interfacial shear strength $(\tau)$. The experimental results validate the reproducibility of the fabrication process given the homogeneity of materials (Fig. 11). The full width at half maximum and the area of the cycles follow a comparable evolution, even though the full width at half maximum saturates for high loading levels. On the contrary, the areas evolution is linear over $0.1 \%$ strain.

Fig. 10.

Fig. 11.

\subsection{Crack density}

The crack density, i.e. the inverse of the mean distance between cracks, was measured, either on the tubes surfaces (internal or external) or in its core. The matrix multicracking is directly related to the type and to the density of defects in the materials and follows a Weibull's distribution. Discrepancies in the crack density between the core (low matrix volume) and the surface (high matrix volume) are observed. Fig. 12 presents a microscopic observation of the crack density for a tested specimen after ultimate failure. The crack density was also observed on samples that were damaged at several levels of longitudinal strain $(0.1 \%, 0.2 \%, 0.3 \%, 0.4 \%$ and $0.5 \%)$. However, in this case, the matrix multicracking is hardly observable in the sample core because of the important cracking closure phenomena, even after chemical etching (Murakami's reagent). This explains why only the crack density at the surface of the tested specimen was retained. In Fig. 13, the evolution of crack density as a function of the applied stress, either on the internal (filament winding) or on the external (2D braiding) sides, are plotted. No obvious differences were noted in the crack density between both sides. The first cracks appear over a $110 \mathrm{Mpa}$ applied stress. The comparison between the normalized crack density (i) and the normalized $\mathrm{AE}$ (ii) as a function of the applied stress is also plotted in Fig. 13 . The same evolution is observed, which confirms that the counting of the AE events is a good method to evaluate damage kinetics [21]. Therefore, this result highlights that no matrix multicracking saturation appear until the material failure, even though the reduced modulus and the full width at half maximum may evidence this saturation. It 
seems that cracks generated above $200 \mathrm{MPa}$ or $0.5 \%$ strain do not have any influence on the evolution of reduced modulus or full width at half maximum during cycled tensile tests. However, it could explain the continuous evolution of the area of cycles and the anelastic residual strains up to complete failure of specimens. This results is consistent with results previously obtained $[42,46]$.

\section{Fig. 12.}

Fig. 13.

4. Discussion

The saturation of AE energy [24] can explain the saturation of reduced modulus, full width at half maximum, irreversible sliding and anelastic residual strains. Nevertheless, the cumulative AE signal do not saturate at high stress or strain $(<200 \mathrm{MPa})$ and is a sign of a specific damage mechanism that still occur, up to complete failure of specimen (Fig. 8). This could explain the absence of saturation of the anelastic residual strains and the area of cycles signals at high stress (> $200 \mathrm{MPa}$ ).

To evaluate the residual thermal stress generated in specimen during processing (due to discrepancies between the thermochemical properties of the fibers, the interphase and the matrix), an analytical model similar to the one used by Michaux [26] was employed. The main difference is that the evolution of the thermochemical properties with temperature was taken into account: longitudinal and transverse Young's modulus and coefficient of thermal expansion, Poisson's ratio. In this model, the sample is assimilated to a microcomposite (one fiber + interphase + matrix) of infinite length. Three different components of the residual thermal stresses are calculated and evaluated: longitudinal $\left(\sigma_{\mathrm{zz}}\right)$, radial $\left(\sigma_{\mathrm{rr}}\right)$ and circumferential $\left(\sigma_{\theta \theta}\right)$. All the thermochemical properties as a function of temperature were fitted with Eq. (3):

$A, B, C, D, E, F$ and $G$ are constants, $T$ the temperature $\left({ }^{\circ} \mathrm{C}\right)$ and $Y$ the thermochemical property. Table 3 summarize the constants used for the calculations. All the lacking constants are equal to zero. $E_{l}$ and $E$ are the longitudinal and transverse Young's moduli, respectively, $\alpha_{l}$ and $\alpha_{t}$ are the longitudinal and transversal coefficients of thermal expansion and Poisson's ratios $\left(v_{12}\right.$ and $\left.v_{13}\right)$ are supposed to be similar for a same material, whatever the direction. The latter assumption is true for isotropic materials 
(SiC fiber and matrix) but is an estimation for pyrocarbon. Anyway, variation of Poisson's ratios do not highly influence the calculation. The different parameters are presented in Table 3 [28].

\section{Table 3}

One should notice that this model cannot be rigorously applied to the tubular 2D shaped composites processed. However, the stress levels are representative of what is achieved after processing. Moreover, for these macroscopic composites, the stresses can be locally highly affected by the material microstructure (presence of pores) [47].

The evaluated thermal stresses are plotted in Fig. 14. The matrix volume fraction was taken equal to that of the fibers, given that this is almost the case for macroscopic composites. The fiber is slightly under tensile stress in all directions, whereas the matrix is under longitudinal and circumferential compression stresses along with low tensile stresses in the radial direction. Higher stress levels are observed in the pyrocarbon interphase with elevated circumferential tension and longitudinal compression. However, those relatively strong stresses in the interphase (up to $170 \mathrm{MPa}$ ) are not sufficient to damage the pyrocarbon interphase during the cool down to room temperature [48]. The thermomechanical properties of the HNS fibers being close to the SiC matrix one, the longitudinal residual thermal stresses remain low as expected. A $35 \pm 5 \mathrm{MPa}$ longitudinal residual thermal stress was experimentally determined by the crossing of the curves asymptotes at the end the loading sequences of the cycled tensile tests (§ 3.B). Those calculations on a microcomposite gave a $30 \mathrm{MPa}$ residual thermal stresses. Therefore, it is noted that even by applying this simple model, the residual thermal stresses determined experimentally are probably representatives. Fig. 14.

The cumulative AE count is proportional to the number of cracks generated in the composite [40]. Thus, the linearity of the $\mathrm{AE}$ count could evidence the lack of matrix multicracking saturation for these $\mathrm{SiC} / \mathrm{SiC}$ samples, on the contrary to the behavior observed of some other similar SiC/SiC composites [21]. It should be noted that the acquisition device only allows a simple event counting over a predefined threshold. The analysis of the AE energy signal (rather than AE cumulative count) for similar tests (analogous materials and mounting) exhibit a saturation above a stress of $200 \mathrm{MPa}$ and a $0.5 \%$ longitudinal strain [24]. However, deviation from linearity at the beginning of the tensile test 
stress/strain curve appears before the first AE signal for all the samples and is not due to the beginning of matrix multicracking (Fig. 15). Table 4 summarizes the values (minimum, maximum and mean) of the stresses and strains reached either at the end of the linear elastic domain or at the first count of the AE signal, revealing the onset of matrix cracking. A mean longitudinal strain and stress of $0.012 \%$ and $34 \mathrm{MPa}$ are respectively measured for the beginning of the deviation from linearity, instead of $0.053 \%$ and $112 \mathrm{MPa}$ for the first count of AE signal. This notable difference was observed neither on similar 1D [27] [44] or 2.5D SiC/SiC composites plates [45] [49], nor on 2.5D braided SiC/SiC tubes [21], even though they share the same interface and fiber type. This specific behavior is then a characteristic of the process used in this study. Therefore, a phenomenon, non-detectable by AE, occurs which leads to a slight rigidity loss before the onset of the matrix cracking.

Fig. 15.

\section{Table 4}

This may originate from pre-existing cracks in the material as it could be observed in $\mathrm{C} / \mathrm{C}[50,51]$ or $\mathrm{C} / \mathrm{SiC}$ materials [29]. The estimated residual thermal stresses due to mismatch between the fibers, pyrocarbon interphase and the matrix (§ 3.B.) are very low and cannot be the source of pre-existing cracks in the matrix after processing. An untested $\mathrm{SiC} / \mathrm{SiC}$ tube specimen was cut in half along its axis of revolution, enrobed in an epoxide resin, polished and analyzed along its longitudinal section by optical microscopy (Fig. 16 (a)). The sample shows clearly the presence of longitudinal cracks of small opening (along the tube axis of revolution). The same observation was carried out on a tube after the consolidation process, i.e. after the interphase and few micrometers of matrix deposition (Fig. 16 (b)). Again, the same type of cracks is observed. Therefore, it can be concluded that they are generated during this first CVI processing step. Even though the following process steps (densification) diminish their opening, these microcracks remain after the last step of the $\mathrm{SiC} / \mathrm{SiC}$ tubes manufacture.

Fig. 16.

This result is related to the specific processing route employed. Indeed, the texture shaping is manufactured on a silica glass mandrel (§ 2.A.a.) and the consolidation step is carried out at about $1000^{\circ} \mathrm{C}$. Then, during the cooling step to room temperature of the sample, residual thermal stresses are 
generated in both the silica glass mandrel and the composite, which have different thermomechanical properties. To estimate those stress values, the model previously used, was employed, considering a one layer microcomposite. In this case, the fiber was replaced by the silica glass mandrel of an external diameter of $8 \mathrm{~mm}$ and the composite represents the layer $(0.75 \mathrm{~mm})$ in contact with the glass. The composite thermomechanical characteristics at the consolidated state being unknown, it was decided to use the thermal expansion and Poisson's coefficients of the HNS fiber. An elastic modulus of $120 \mathrm{GPa}$ was retained, given the low densification at the end of this processing step (high volume fraction of porosity). Eq. (3) was again used to determine the evolution of the thermomechanical properties as a function of temperature. The constants used for this calculation are given in Table 5. The silica mandrel thermochemical properties were extracted from [52]. The SiC/SiC ones in the consolidated state were extrapolated from those of the manufactured $\mathrm{SiC} / \mathrm{SiC}$ by taking into account the level of densification.

\section{Table 5}

The simulation result is plotted in Fig. 17. The composite obtained after the consolidation step encounters high residual thermal stresses, especially in circumferential and longitudinal directions. Those high residual thermal stresses after the consolidation step explain the origin of the matrix initial cracks observed in Fig. 17. Bernachy et al. [24] highlighted that, for this type of bi-axial solicitation (tensile - internal pressure), the microcracks are perpendicular to the principal solicitation axis (internal pressure loading), which is consistent with the cracks observed in Fig. 16 (a) and (b), following the tube axis (perpendicular to the internal pressure loading generated by the mismatch in the thermomechanical properties).

Fig. 17.

\section{Conclusions}

The nuclear reactors cladding may be subjected to strong thermomechanical stresses during the set up of the fuel, operation and especially in transient or accidental states. In order to assess the viability of $\mathrm{SiC} / \mathrm{SiC}$ composites as cladding material, its mechanical behavior under uniaxial tensile solicitation was characterized. Even though the matrix was deposited by CVI, the final material porosity volume fraction remains low (6.6\%). The strain - stress curves show a high reproducibility of the mechanical behavior, with a pseudo-elastic behavior and relatively high longitudinal strain and stress levels at fracture (resp. 
$1.01 \%$ and $279 \mathrm{MPa}$ ). The elastic modulus strongly decrease after the first microcracks are generated in the matrix but its value tends to an asymptote over 150-200 MPa. However, the area of the cycles, relevant of the friction mechanisms within the composite, still increase at the last cycle before ultimate fracture. This result was confirmed by the analysis of the crack density that evolves along with the cumulated acoustic emission signal since the first microcracks are generated in the material. Therefore, the composites of this study do not present any matrix multicracking saturation. Thanks to a small mismatch between the thermomechanical properties of the Hi-Nicalon $\mathrm{S}$ fibers and the matrix, the manufactured composites have low residual thermal stresses, which was confirmed by both modelling and the cycled tensile tests analysis. A loss of linearity before the appearance of the first AE signal was observed, which was not observed on 1D or 2.5D similar composites. This phenomenon was attributed to the presence of small cracks in the as fabricated composite, which originated from the first CVI processing step (before the mandrel withdrawal) and is the consequence of the use of silica as mandrel for fibrous reinforcement structure processing. This assessment of the mechanical properties of the manufactured $\mathrm{SiC} / \mathrm{SiC}$ cladding tubes will be take into consideration to evaluate the influence of nuclear environments on the materials, such as the liquid sodium at nominal operating temperature of SFR, in further studies. 
References

[1] Cavalier JC, Berdoyes I, Bouillon E. Composites in aerospace industry. Ind Ceram 2009;29:119-26.

[2] Zok FW. Ceramic-matrix composites enable revolutionary gains in turbine engine efficiency. Am Ceram Soc Bull 2016;95:22-28.

[3] Staehler JM, Zawada LP. Performance of four ceramic-matrix composite divergent flap inserts following ground testing on an F110 turbofan engine. J Am Ceram Soc 2000;83:1727-1738.

[4] Sauder C. Ceramic Matrix Composites: Nuclear Applications. Ceram. Matrix Compos. Mater. Model. Technol. Appl., Wiley, Hoboken, NJ: Narottam P. Bansal and Jacques Lamon; 2014.

[5] Hironaka K, Nozawa T, Hinoki T, Igawa N, Katoh Y, Snead LL, et al. High-temperature tensile strength of near-stoichiometric SiC/SiC composites. J Nucl Mater 2002;307:10931097.

[6] Opila EJ, Hann Jr. RE. Paralinear oxidation of CVD SiC in water vapor. J Am Ceram Soc 1997;80:197-205.

[7] Giancarli L, Aiello G, Caso A, Gasse A, Le Marois G, Poitevin Y, et al. R\&D issues for $\mathrm{SiCf} / \mathrm{SiC}$ composites structural material in fusion power reactor blankets. Fusion Eng Des 2000;48:509-520.

[8] Katoh Y, Snead LL, Henager CH, Hasegawa A, Kohyama A, Riccardi B, et al. Current status and critical issues for development of SiC composites for fusion applications. J Nucl Mater 2007;367-370:659-71.

[9] Terrani KA. Accident tolerant fuel cladding development: Promise, status, and challenges. J Nucl Mater 2018;501:13-30.

[10] Gasparini M, International Atomic Energy Agency. IAEA. Considerations in the development of safety requirements for innovative reactors: application to modular high temperature gas cooled reactors. 2003.

[11] Katoh Y, Snead LL, Henager CH, Nozawa T, Hinoki T, Iveković A, et al. Current status and recent research achievements in SiC/SiC composites. J Nucl Mater 2014;455:387-97.

[12] Snead LL, Katoh Y, Nozawa T. Radiation Effects in SiC and SiC-SiC. Compr. Nucl. Mater., vol. 4, R.J. M. Konings (Elsevier Ltd); 2012, p. 215-39.

[13] Wimpory RC, Ohms C, Horňák P, Neov D, Youtsos A. Residual Strain Measurement of C/CSiC Tubes at High Temperature. Mater Sci Forum 2006;524-525:665-70.

[14] Ortona A, Fend T, Yu H-W, Raju K, Yoon D-H. Fabrication of cylindrical SiCf/Si/SiC-based composite by electrophoretic deposition and liquid silicon infiltration. J Eur Ceram Soc 2014;34:1131-8.

[15] Deck CP, Khalifa HE, Sammuli B, Hilsabeck T, Back CA. Fabrication of SiC-SiC composites for fuel cladding in advanced reactor designs. Prog Nucl Energy 2012;57:38-45.

[16] Katoh Y. Ceramic matrix composites in fission and fusion energy applications. Adv. Ceram. Matrix Compos., Elsevier; 2018, p. 595-622.

[17] Yun HM, DiCarlo JA, Fox DS. Issues on Fabrication and Evaluation of SiC/SiC Tubes With Various Fiber Architectures 2004

[18] Yu H-W, Fitriani P, Lee S, Park J-Y, Yoon D-H. Fabrication of the tube-shaped SiCf/SiC by hot pressing. Ceram Int 2015;41:7890-6.

[19] Sha J., Nozawa T, Park J., Katoh Y, Kohyama A. Effect of heat treatment on the tensile strength and creep resistance of advanced SiC fibers. J Nucl Mater 2004;329-333:592-6.

[20] Nakazato N, Kishimoto H, Kohno Y, Kohyama A. Sic/Sic Fuel Cladding by Nite Process for Innovative LWR-Cladding Forming Process Development. Ceram. Environ. Energy Appl. II, Wiley-Blackwell; 2014, p. 109-15. 
[21] Rohmer E, Martin E, Lorrette C. Mechanical properties of $\mathrm{SiC} / \mathrm{SiC}$ braided tubes for fuel cladding. J Nucl Mater 2014;453:16-21.

[22] Feinroth $H$, Ales $M$, Barringer E, Kohse G, Carpenter D, Jaramillo R. Mechanical strength of CTP Triplex SiC fuel clad tubes after irradiation in MIT research reactor under PWR coolant conditions. Ceram. Eng. Sci. Proc., vol. 30, 2009, p. 47.

[23] Jacobsen GM, Stone JD, Khalifa HE, Deck CP, Back CA. Investigation of the C-ring test for measuring hoop tensile strength of nuclear grade ceramic composites. J Nucl Mater 2014;452:125-32.

[24] Bernachy-Barbe F, Gélébart L, Bornert M, Crépin J, Sauder C. Anisotropic damage behavior of $\mathrm{SiC} / \mathrm{SiC}$ composite tubes: Multiaxial testing and damage characterization. Compos Part Appl Sci Manuf 2015;76:281-8.

[25] Morscher GN. Modal acoustic emission of damage accumulation in a woven $\mathrm{SiC} / \mathrm{SiC}$ composite. Compos Sci Technol 1999;59:687-97.

[26] Michaux A, Sauder C, Camus G, Pailler R. Young's modulus, thermal expansion coefficient and fracture behavior of selected $\mathrm{Si}-\mathrm{B}-\mathrm{C}$ based carbides in the $20-1200^{\circ} \mathrm{C}$ temperature range as derived from the behavior of carbon fiber reinforced microcomposites. J Eur Ceram Soc 2007;27:3551-60.

[27] Sauder C, Lorrette C. Patent: Method for producing a composite including a ceramic matrix. WO2012/119805 A1, 2012.

[28] Buet E, Sauder C, Sornin D, Poissonnet S, Rouzaud J-N, Vix-Guterl C. Influence of surface fibre properties and textural organization of a pyrocarbon interphase on the interfacial shear stress of $\mathrm{SiC} / \mathrm{SiC}$ minicomposites reinforced with Hi-Nicalon $\mathrm{S}$ and Tyranno SA3 fibres. J Eur Ceram Soc 2014;34:179-88.

[29] ISO 20323. Fine ceramics (advanced ceramics, advanced technical ceramics) - Mechanical properties of ceramic composites at ambient temperature in air atmospheric pressure Determination of tensile properties of tubes.

[30] Camus G, Guillaumat L, Baste S. Development of damage in a 2D woven C/SiC composite under mechanical loading: I. Mechanical characterization. Compos Sci Technol 1996;56:1363-72.

[31] Baste S. Inelastic behaviour of ceramic-matrix composites. Compos Sci Technol 2001;61:2285-97.

[32] Fantozzi G, Reynaud P. Mechanical hysteresis in ceramic matrix composites. Mater Sci Eng A 2009;521-522:18-23.

[33] Bertrand S, Forio P, Pailler R, Lamon J. Hi-Nicalon/SiC minicomposites with (Pyrocarbon/SiC) n nanoscale multilayered interphases. J Am Ceram Soc 1999;82:24652473.

[34] Domergue J-M, Vagaggini E, Evans AG. Relationships between Hysteresis Measurements and the Constituent Properties of Ceramic Matrix Composites: II, Experimental Studies on Unidirectional Materials. J Am Ceram Soc 1995;78:2721-31.

[35] Lynch CS, Evans AG. Effects of Off-Axis Loading on the Tensile Behavior of a CeramicMatrix Composite. J Am Ceram Soc 1996;79:3113-23.

[36] Gudmundson P, Östlund S. Prediction of thermoelastic properties of composite laminates with matrix cracks. Compos Sci Technol 1992;44:95-105.

[37] Kuo W-S, Chou T-W. Modeling of Nonlinear Constitutive Relations of Woven Ceramic Composites. In: Jr JBW, editor. Proc. 15th Annu. Conf. Compos. Adv. Ceram. Mater. Ceram. Eng. Sci. Proc., John Wiley \& Sons, Inc.; 1991, p. 1556-73.

[38] Bouquet M, Birbis JM, Quenisset JM. Toughness assessment of ceramic matrix composites. Compos Sci Technol 1990;37:223-48.

[39] Aubard X, Lamon J, Allix O. Model of the nonlinear mechanical behavior of 2D SiC-SiC chemical vapor infiltration composites. J Am Ceram Soc 1994;77:2118-2126. 
[40] Morscher GN, Martinez-Fernandez J. Fiber effects on minicomposite mechanical properties for several silicon carbide fiber-chemically vapor-infiltrated silicon carbide matrix systems. J Am Ceram Soc 1999;82:145-155.

[41] Curtin WA. Theory of Mechanicla Properties of Ceramic-Matrix Composites. J Am Ceram Soc 1991;74:2837-45.

[42] Moevus M, Godin N, R'Mili M, Rouby D, Reynaud P, Fantozzi G, et al. Analysis of damage mechanisms and associated acoustic emission in two SiCf/[Si-B-C] composites exhibiting different tensile behaviours. Part II: Unsupervised acoustic emission data clustering. Compos Sci Technol 2008;68:1258-65.

[43] Buet E, Sauder C, Poissonnet S, Brender P, Gadiou R, Vix-Guterl C. Influence of chemical and physical properties of the last generation of silicon carbide fibres on the mechanical behaviour of SiC/SiC composite. J Eur Ceram Soc 2012;32:547-57.

[44] Sauder C, Brusson A, Lamon J. Influence of interface characteristics on the mechanical properties of Hi-Nicalon type-S or Tyranno-SA3 fiber-reinforced SiC/SiC minicomposites: influence of interface characteristics on the mechanical properties. Int J Appl Ceram Technol 2010;7:291-303.

[45] Kostopoulos V, Vellios L, Pappas YZ. Fatigue behaviour of 3-d SiC/SiC Composites n.d.:6.

[46] Momon S, Godin N, Reynaud P, R'Mili M, Fantozzi G. Unsupervised and supervised classification of $A E$ data collected during fatigue test on $\mathrm{CMC}$ at high temperature. Compos Part Appl Sci Manuf 2012;43:254-60.

[47] Gélébart L, Colin C. Effects of porosity on the elastic behaviour of CVI SiC/SiC composites. J Nucl Mater 2009;386-388:82-5.

[48] Sauder C, Lamon J, Pailler R. The tensile properties of carbon matrices at temperatures up to $2200^{\circ} \mathrm{C}$. Carbon 2005;43:2054-65.

[49] Ruggles-Wrenn MB, Christensen DT, Chamberlain AL, Lane JE, Cook TS. Effect of frequency and environment on fatigue behavior of a $\mathrm{CVI} \mathrm{SiC/SiC} \mathrm{ceramic} \mathrm{matrix}$ composite at $1200^{\circ} \mathrm{C}$. Compos Sci Technol 2011;71:190-6.

[50] Siron O. Modelling of the stress/strain behaviour of a carbon/carbon composite with a 2.5 dimensional fibre architecture under tensile and shear loads at room temperature. Compos Sci Technol 1999:12.

[51] Siron O, Lamon J. Damage and failure mechanisms of a3-directional carbon/carbon composite under uniaxial tensile and shear loads. Acta Mater 1998;46:6631-43.

[52] Vof Micro to Nano, Technical information for type GE 124 fused quartz, TSB 100815-1, 
Fig. Captions
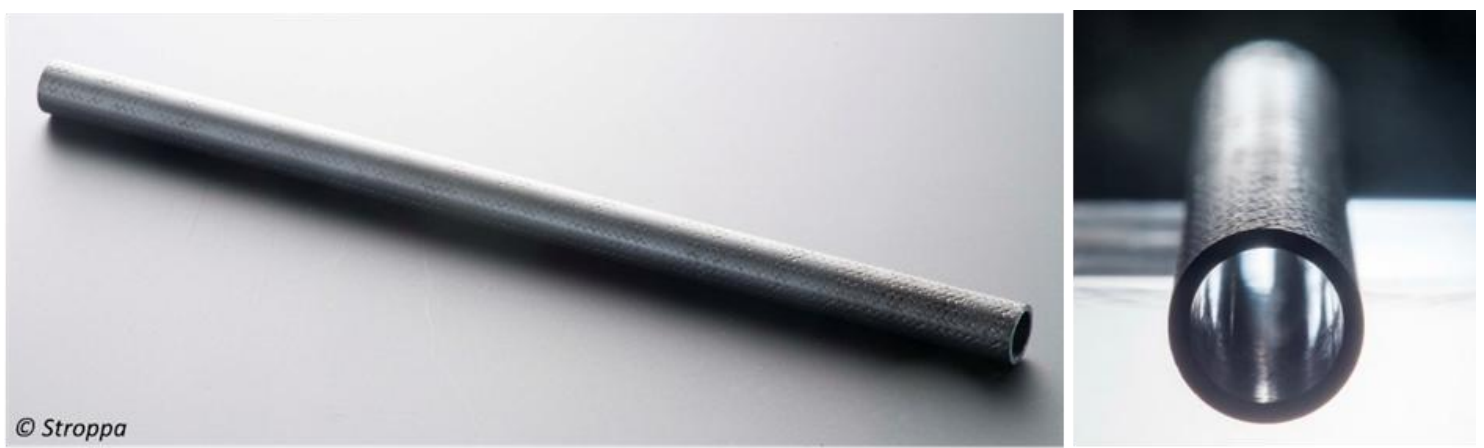

Fig. 1. SiC/SiC composites tubes as processed.

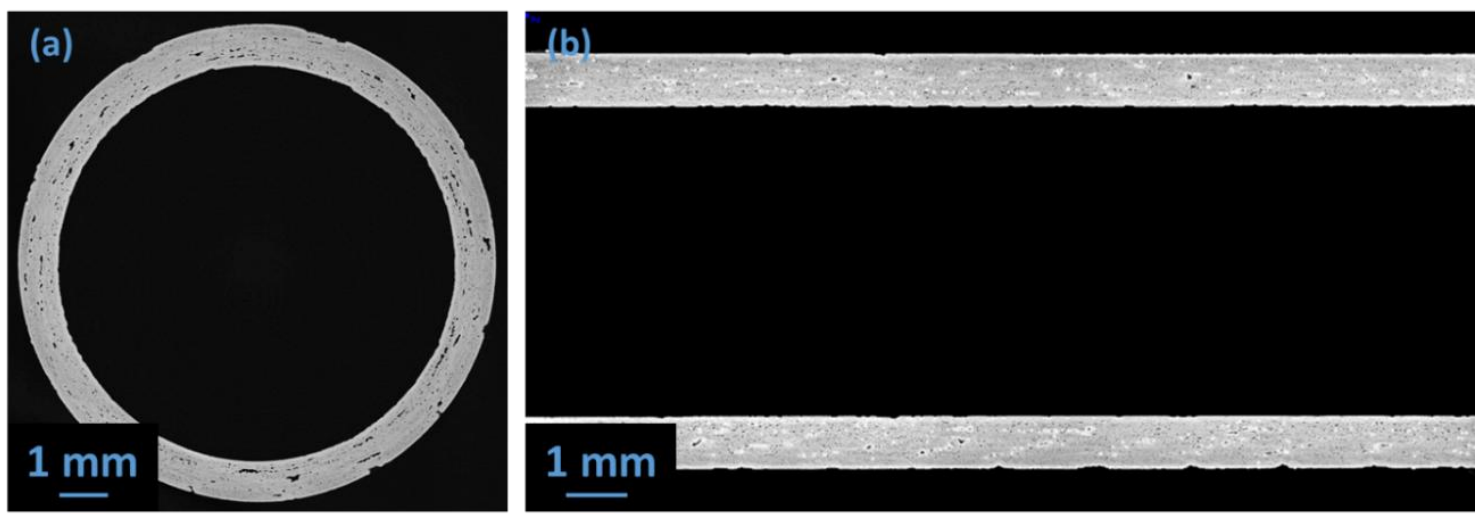

Fig. 2. X-ray tomography of the manufactured $\mathrm{SiC} / \mathrm{SiC}$ clad cross-section perpendicular to (a) and along

(b) its axis of revolution, respectively. 


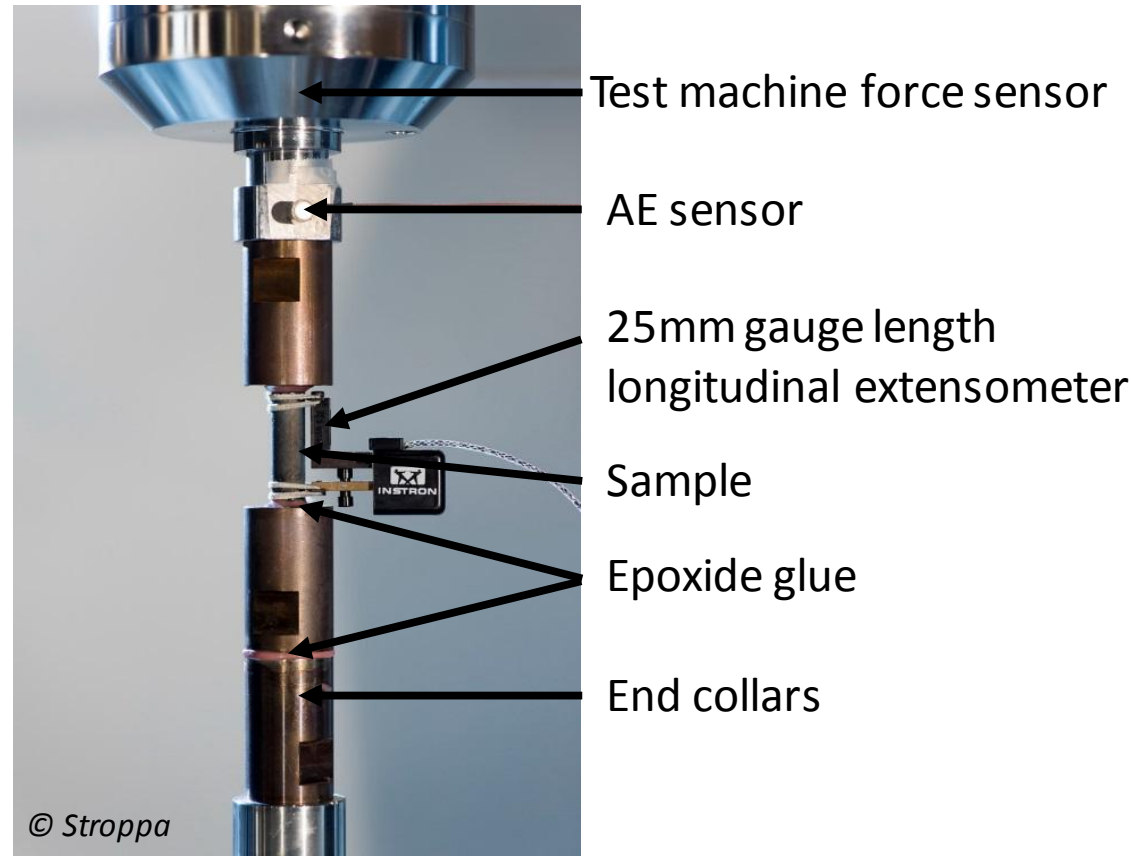

Fig. 3. Experimental device employed for tensile testing, without diametric extensometer

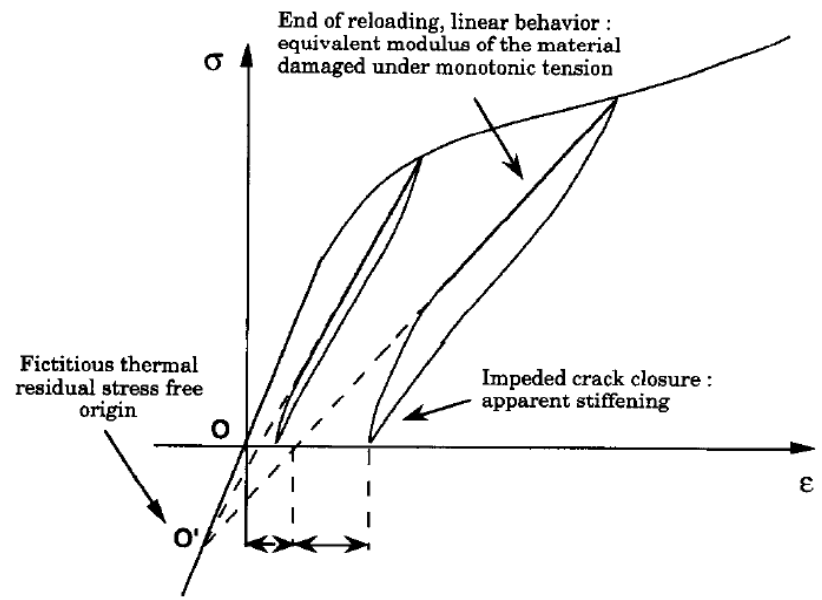

Fig. 4. Schematic representation of unloading - reloading cycles hysteresis loop with associated equivalent modulus and anelastic residual strain $\varepsilon_{a n}$ in a CMC. $\varepsilon_{t}$ and $\varepsilon_{f}$ represent the permanent strains due to release of the thermal residual stresses and to partial irreversible sliding, respectively [29]. 


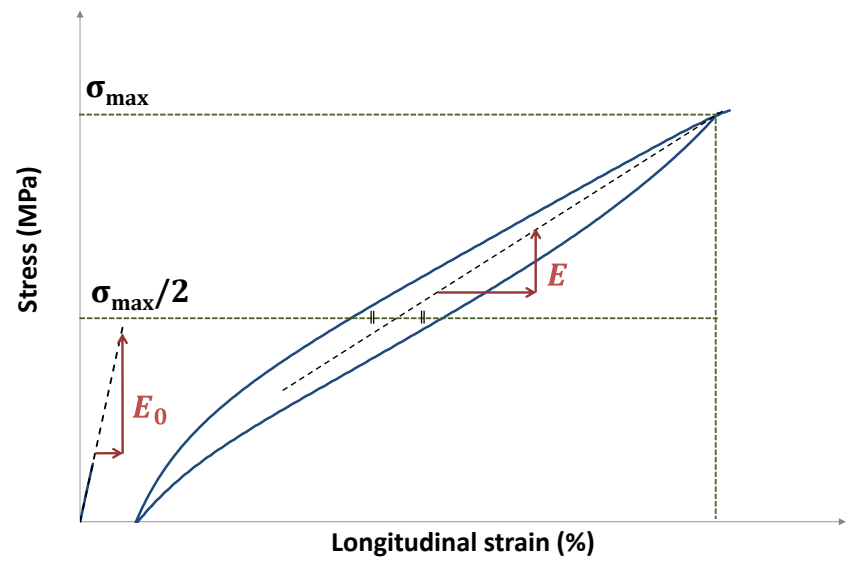

Fig. 5. Determination of the initial Young's $\left(E_{0}\right)$ and the elastic modulus $(E)$ for a given cycle.

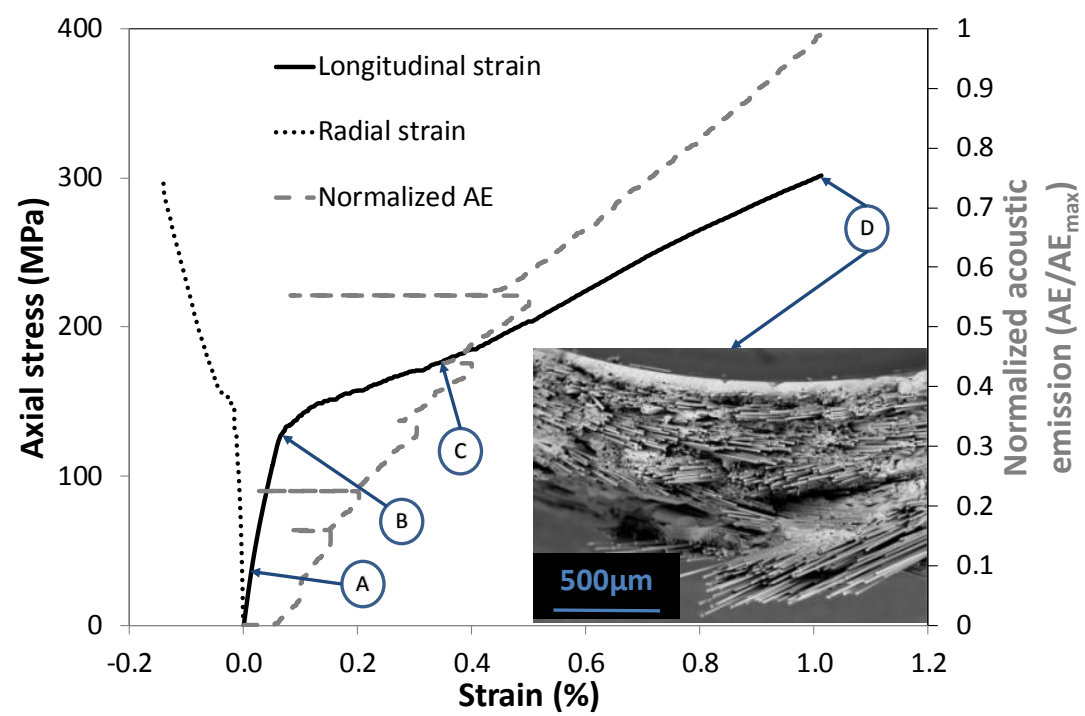

Fig. 6. Typical tensile strain - stress curves (envelope of the cycled tests) along with the evolution of normalized $A E$ on a reference sample (REF 3) and the fracture surface after mechanical solicitation up to failure. 


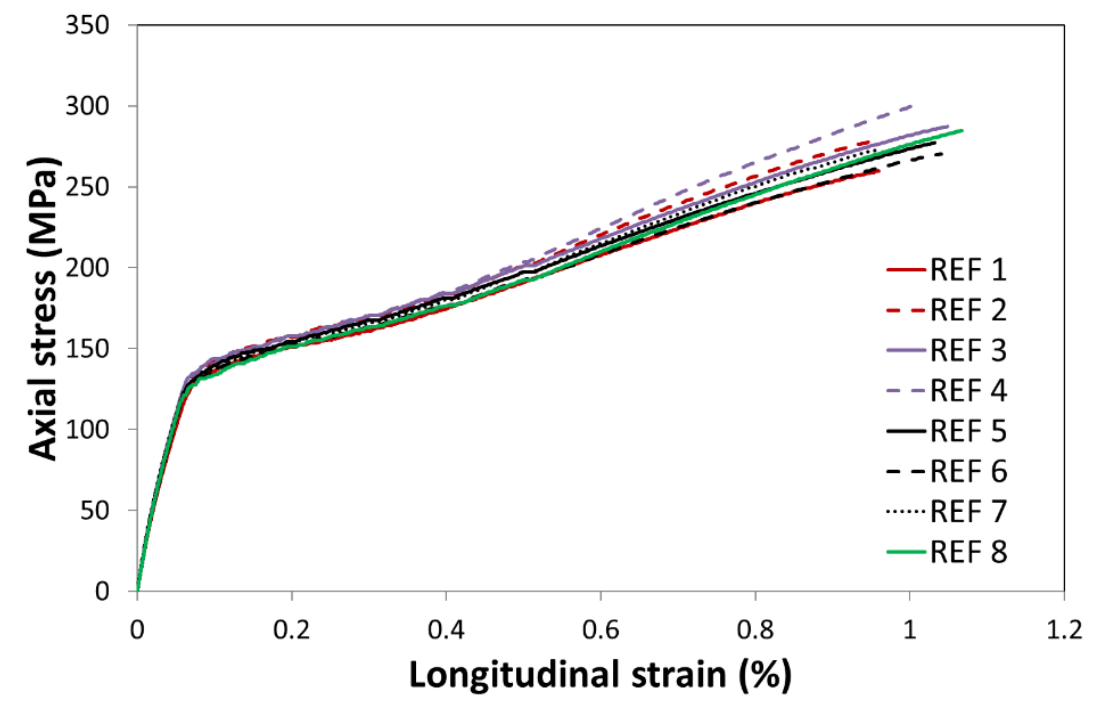

Fig. 7. Tensile stress-strain curves (envelope of cycled tests) for different tubular SiC/SiC specimens.

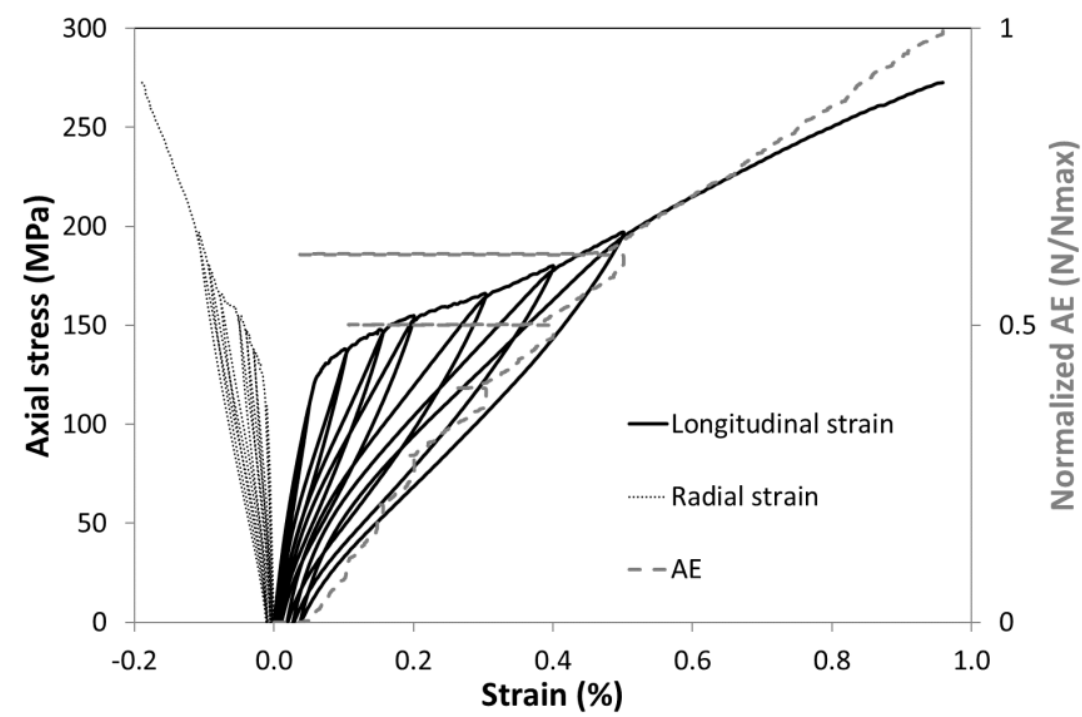

Fig. 8. Typical evolution of tensile stress and normalized AE signal as a function of longitudinal and radial strains for tensile test. 


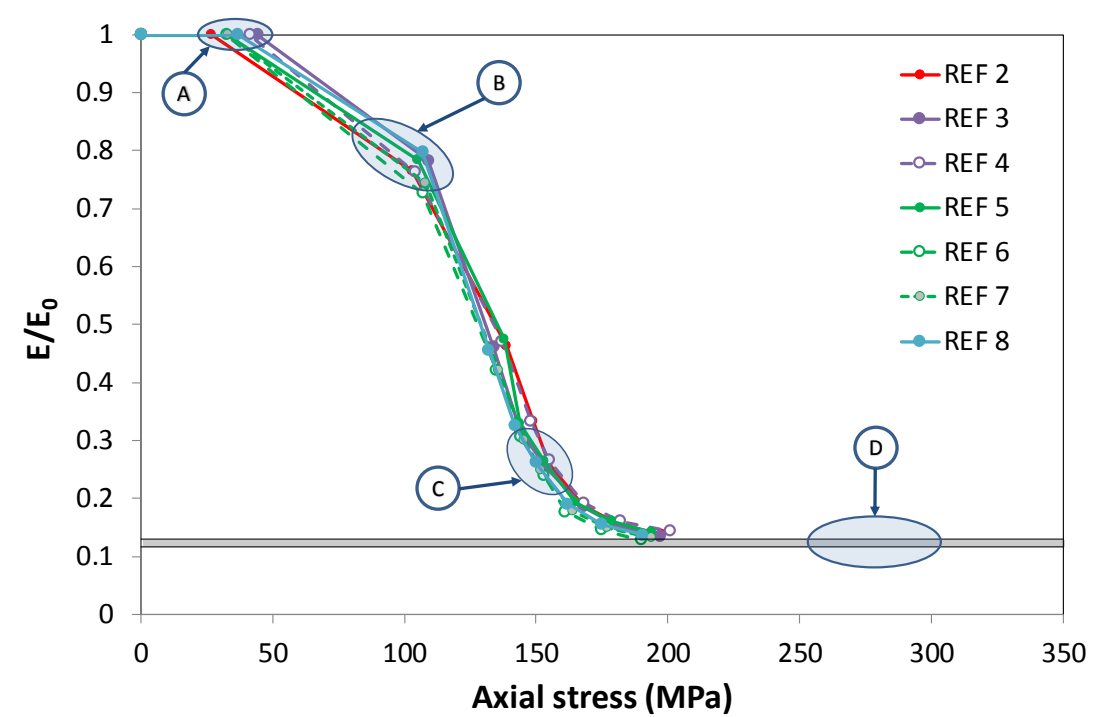

Fig. 9. Evolution of the reduced modulus as a function of the maximum applied stress reached before unloading.
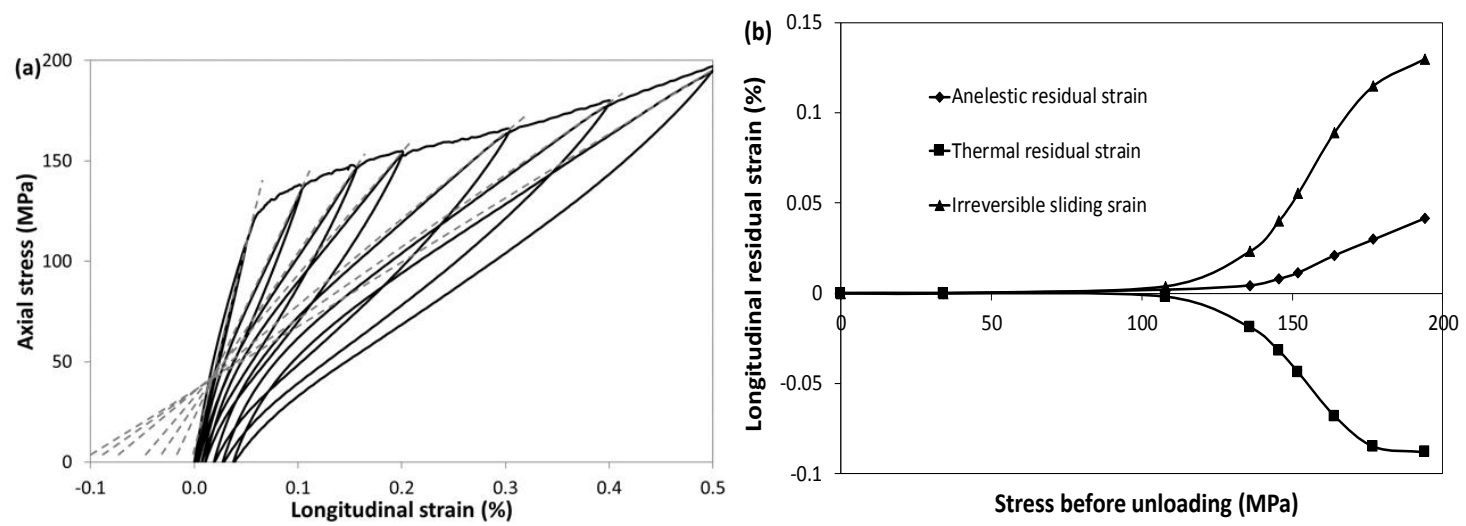

Fig. 10. Tangents at the end of the reloading step allowing the determination of the stress and thermal residual strains (a). Anelastic, sliding and thermal residual strains as a function of the stress reached before unloading (b). 

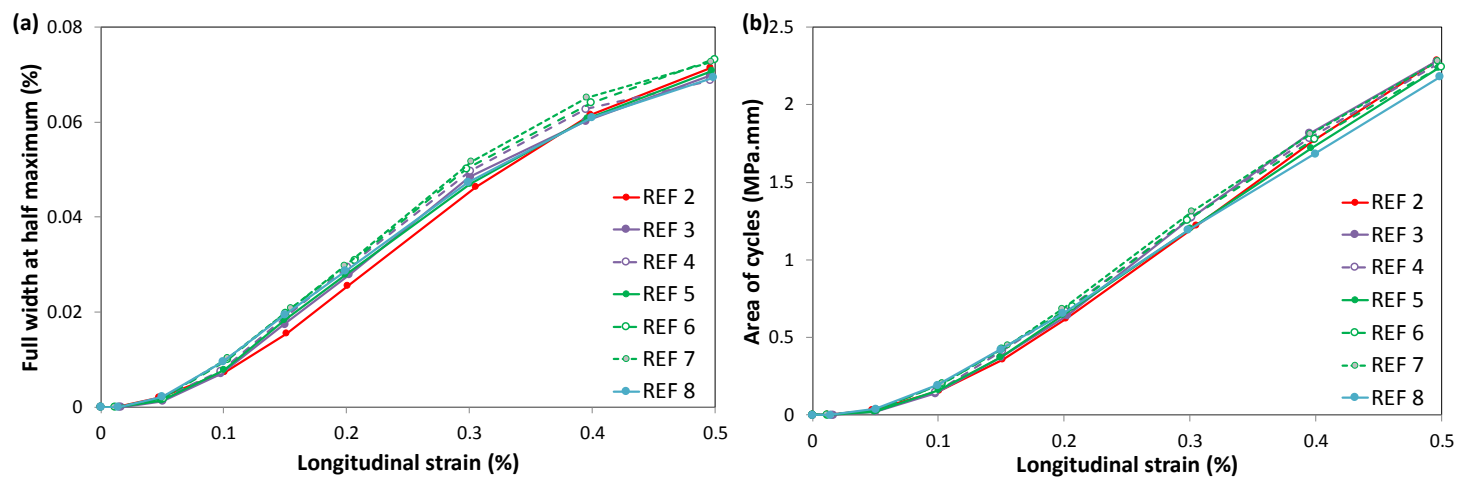

Fig. 11. Evolution of full width at half maximum (a) and area of the cycles (MPa.mm) as a function of the maximum longitudinal strain reached before unloading.

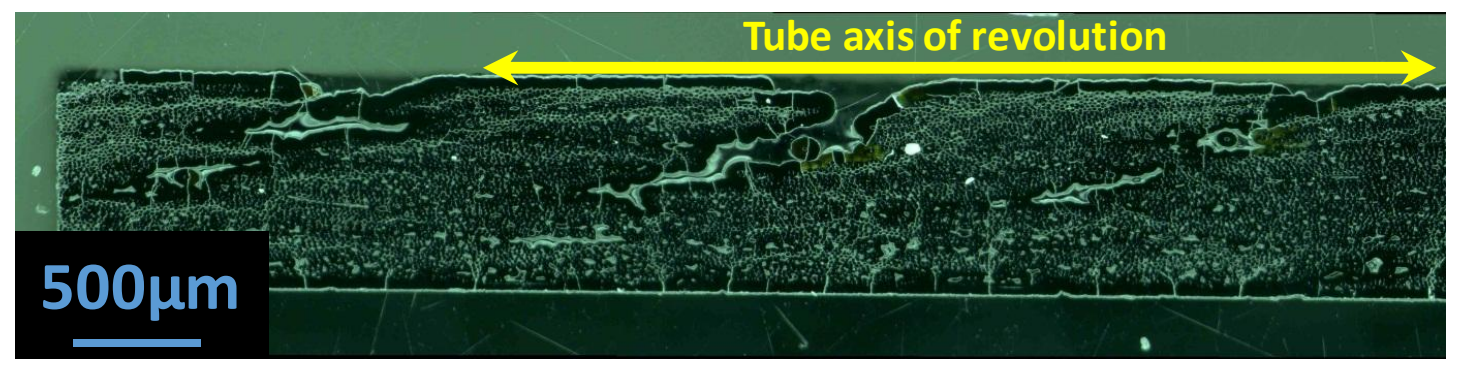

Fig. 12. Surface matrix cracking along the tube axis of revolution.

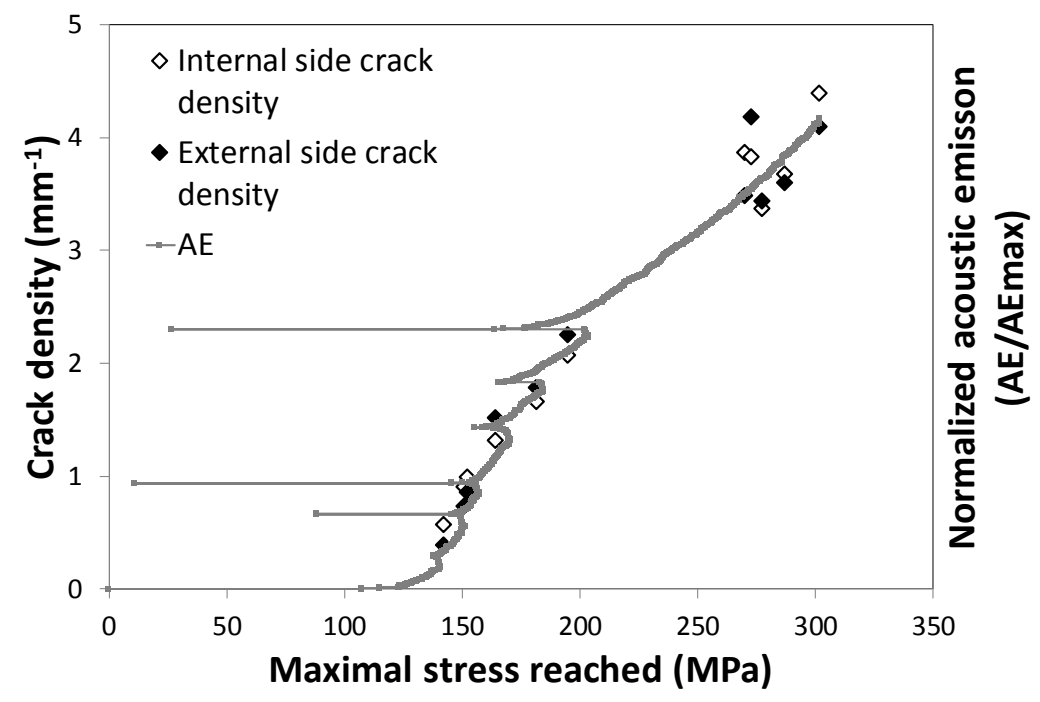

Fig. 13. Evolution of crack density on the internal (filament winding structure) and external (2D braiding structure) sides and comparison with acoustic emission (b) as a function of the maximal axial stress reached. 


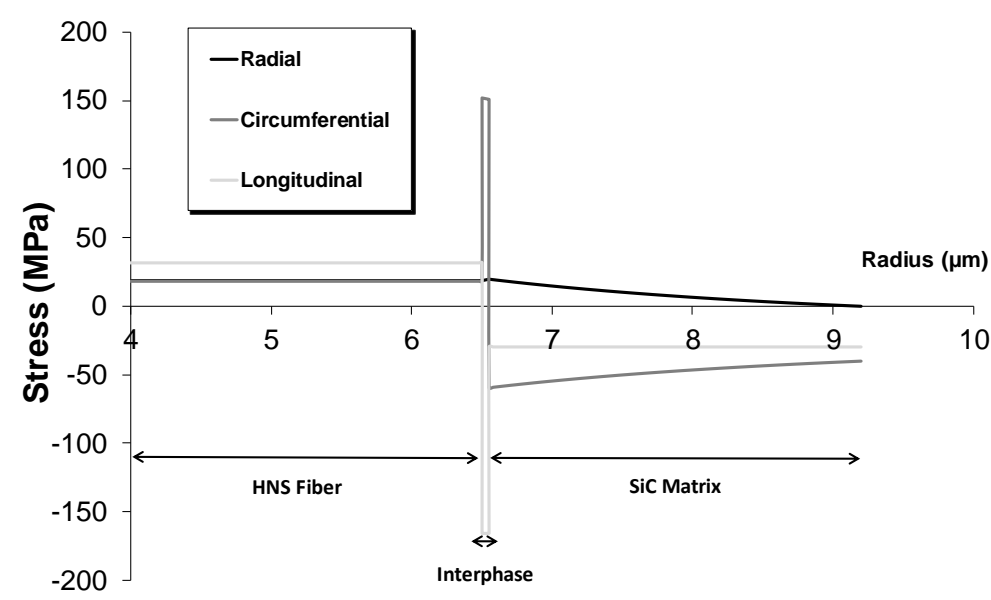

Fig. 14. Radial, circumferential and longitudinal residual thermal stresses calculated in a microcomposite with fiber and matrix equivalent fractions.

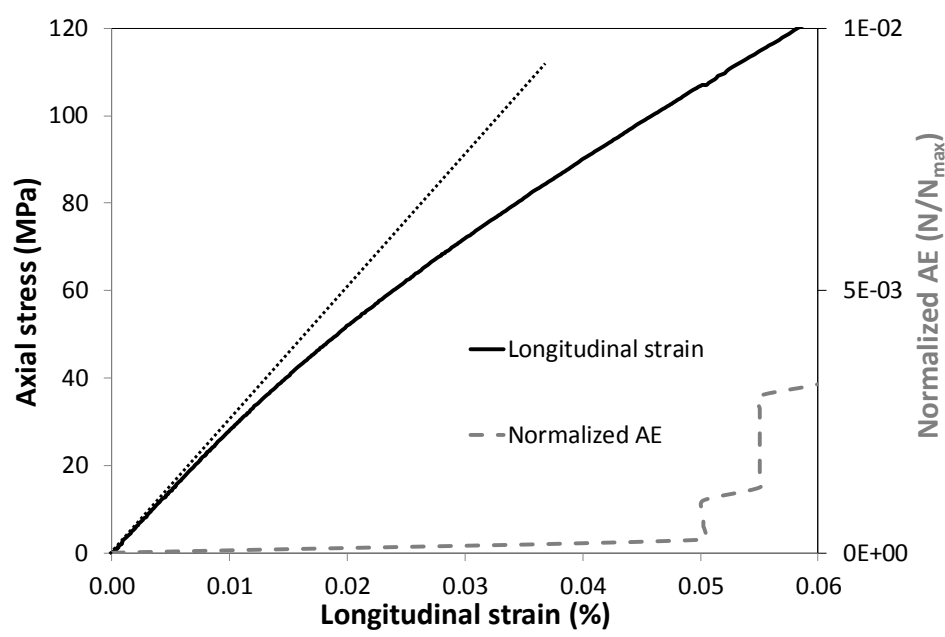

Fig. 15. Discrepancies in the beginning of the matrix multicracking and the end of the strain - stress linearity for a $\mathrm{SiC} / \mathrm{SiC}$ composite tube specimen during uniaxial tensile test. 

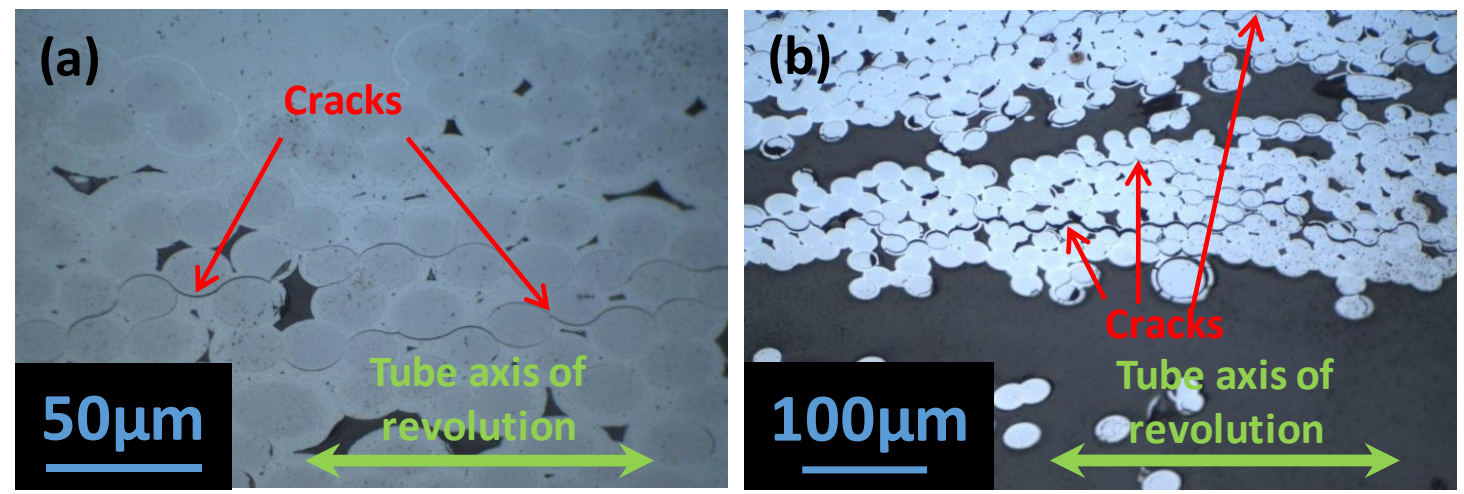

Fig. 16. Cross section of $\mathrm{SiC} / \mathrm{SiC}$ tubes along the axis of revolution after the final densification (a) and the consolidation step (b).

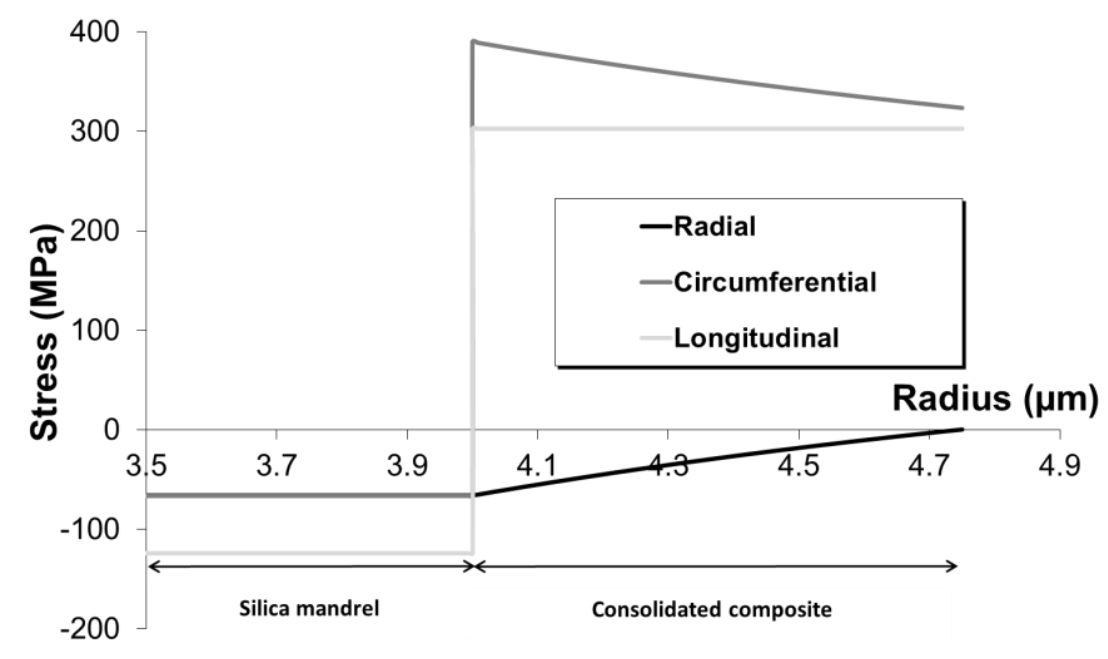

Fig. 17. Evaluation of the thermal residual strains between the silica mandrel and the consolidated composite. 
Tables

Table 1

$\mathrm{SiC} / \mathrm{SiC}$ clads geometrical characteristics mean values and standard deviation.

\begin{tabular}{|c|c|c|c|}
\hline $\begin{array}{c}\text { Outer } \\
\text { diameter }(\mathrm{mm})\end{array}$ & $\begin{array}{c}\text { Inner } \\
\text { diameter }(\mathrm{mm})\end{array}$ & $\begin{array}{c}\text { Density } \\
\left(\mathrm{g} . \mathrm{cm}^{-3}\right)\end{array}$ & $\begin{array}{c}\text { Porosity volume } \\
\text { fraction (\%) }\end{array}$ \\
\hline 9.58 & 7.88 & 2.90 & 6.61 \\
\hdashline$(0.02)$ & $(0.01)$ & $(0.03)$ & $(0.87)$ \\
\hline
\end{tabular}

Table 2

Main characteristics of the tensile behavior for all SiC/SiC tubular specimens.

\begin{tabular}{c|c|c|c|c|c} 
Sample & $\begin{array}{c}\text { Young's } \\
\text { modulus } \\
(\mathrm{GPa})\end{array}$ & $\begin{array}{c}\text { Longitudinal } \\
\text { strain at } \\
\text { fracture }(\%)\end{array}$ & $\begin{array}{c}\text { Diametral } \\
\text { strain at } \\
\text { fracture }(\%)\end{array}$ & $\begin{array}{c}\text { Longitudinal } \\
\text { stress at fracture } \\
\left(\sigma_{f}\right)\end{array}$ & $\begin{array}{c}\text { Poisson's } \\
\text { ratio at } \\
\text { fracture } \\
\left(v_{R}\right)\end{array}$ \\
\hline REF1 & 267 & 0.960 & -0.134 & 260 & 0.14 \\
\hline REF2 & 287 & 0.957 & -0.135 & 278 & 0.14 \\
\hline REF3 & 283 & 1.049 & - & 287 & - \\
\hline REF4 & 279 & 1.013 & -0.144 & 302 & 0.14 \\
\hline REF5 & 272 & 1.033 & -0.138 & 277 & 0.13 \\
\hline REF6 & 290 & 1.041 & -0.179 & 270 & 0.17 \\
\hline REF7 & 293 & 0.959 & -0.189 & 273 & 0.19 \\
\hline REF8 & 275 & 1.067 & -- & 285 & - \\
\hline Average & $\mathbf{2 8 1}$ & $\mathbf{1 . 0 1 0}$ & $-\mathbf{0 . 1 5 3}$ & $\mathbf{2 7 9}$ & $\mathbf{0 . 1 5}$ \\
\hline $\begin{array}{c}\text { Standard } \\
\text { deviation }\end{array}$ & $\mathbf{9}$ & $\mathbf{0 . 0 4 5}$ & $\mathbf{0 . 0 2 4}$ & $\mathbf{1 3}$ & $\mathbf{0 . 0 2}$ \\
\hline
\end{tabular}




\section{Table 3}

Coefficients of the analytic model for the Young's moduli, Poisson's ratio and coefficients of thermal expansion [28].

\begin{tabular}{|c|c|c|}
\hline CVI SiC (matrix) & HNS fiber & Pyrocarbon \\
\hline $\begin{array}{l}D=-9.85 \times 10^{-5} \\
E=1.36 \times 10^{-1} \\
F=-7.11 \times 10^{1} \\
G=4.18 \times 10^{5}\end{array}$ & $\begin{array}{l}D=-8.88 \times 10^{-5} \\
E=1.23 \times 10^{-1} \\
F=-6.41 \times 10^{1} \\
G=3.76 \times 10^{5}\end{array}$ & $\mathrm{G}=1.15 \times 10^{5}$ \\
\hline$=$ & $=$ & $\mathrm{G}=3.0 \times 10^{4}$ \\
\hline 0.2 & 0.2 & 0.3 \\
\hline $\begin{array}{l}E=-4.51 \times 10^{-12} \\
F=9.36 \times 10^{-9} \\
G=1.30 \times 10^{-6}\end{array}$ & $\begin{array}{l}E=-2.25 \times 10^{-12} \\
F=4.75 \times 10^{-9} \\
G=2.91 \times 10^{-6}\end{array}$ & $\begin{array}{l}E=-3.25 \times 10^{-12} \\
F=5.71 \times 10^{-9} \\
G=7.65 \times 10^{-7}\end{array}$ \\
\hline$=$ & $=$ & $\begin{array}{l}F=2.0 \times 10^{-9} \\
G=1.0 \times 10^{-5}\end{array}$ \\
\hline
\end{tabular}

Table 4

Strains and stresses at the end of the linearity domain and at the beginning of the matrix multicracking during uniaxial tensile tests.

\begin{tabular}{c|c|c|c|c}
\multirow{2}{*}{} & \multicolumn{2}{|c|}{$\begin{array}{c}\text { End of the linear elastic domain } \\
\text { on the stress-strain curve }\end{array}$} & \multicolumn{2}{|c}{$\begin{array}{r}\text { Onset of matrix cracking (first Acoustic } \\
\text { Emission signals) }\end{array}$} \\
\cline { 2 - 5 } & $\begin{array}{c}\text { Longitudinal } \\
\text { strain } \varepsilon_{l}(\%)\end{array}$ & Stress $\sigma_{l}$ (MPa) & $\begin{array}{c}\text { Longitudinal } \\
\text { strain } \quad(\%)\end{array}$ & Stress $\quad$ (MPa) \\
\hline Min & 0.009 & 24 & 0.047 & 102 \\
\hline Max & 0.016 & 44 & 0.059 & 122 \\
\hline Average & 0.012 & 34 & 0.053 & 112 \\
\hline SD & 0.002 & 4 & 0.005 & 5 \\
\hline
\end{tabular}




\section{Table 5}

Coefficients of the analytic model for the calculation of the silica mandrel - consolidated composite thermal stresses [52].

\begin{tabular}{|c|c|}
\hline Silica glass mandrel & $\begin{array}{l}\text { Consolidated } \\
\text { composite }\end{array}$ \\
\hline $\begin{array}{l}E=-4.74 \times 10^{-3} \\
F=1.30 \times 10^{1} \\
G=7.27 \times 10^{4}\end{array}$ & $\mathrm{G}=1.20 \times 10^{5}$ \\
\hline$=$ & $=$ \\
\hline 0.18 & 0.2 \\
\hline $\begin{array}{l}A=1.01 \times 10^{-23} \\
B=-3.21 \times 10^{-20} \\
C=3.19 \times 10^{-17} \\
D=-3.80 \times 10^{-15} \\
E=1.00 \times 10^{-11} \\
F=4.14 \times 10^{-9} \\
G=3.73 \times 10^{-7}\end{array}$ & $\begin{array}{l}E=-2.25 \times 10^{-12} \\
F=4.75 \times 10^{-9} \\
G=2.91 \times 10^{-6}\end{array}$ \\
\hline$=$ & $=$ \\
\hline
\end{tabular}

